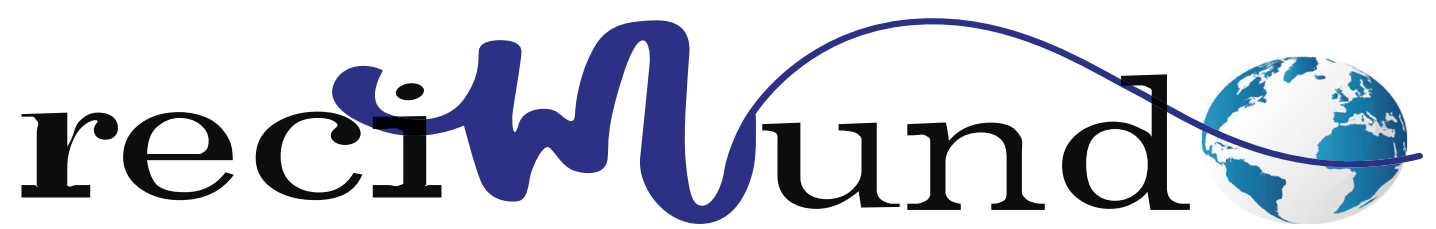

Revista Científica Mundo de la Investigación y el Conocimiento

DOI: 10.26820/recimundo/5.(Suple1).oct.2021.60-74

URL: https://recimundo.com/index.php/es/article/view/1333

EDITORIAL: Saberes del Conocimiento; Universidad Yachay Tech

REVISTA: RECIMUNDO

ISSN: 2588-073X

TIPO DE INVESTIGACIÓN: Artículo de revisión

CÓDIGO UNESCO: 53 Ciencias Económicas

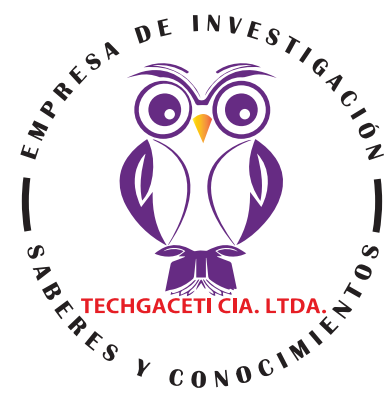

PAGINAS: 60-74

\title{
Covid-19 y mercado laboral ecuatoriano: impacto, esperanzas y oportunidades
}

Covid-19 and the ecuadorian labor market: impact, hopes and opportunities

Covid-19 e mercado laboral ecuatoriano: impacto, esperanças e oportunidades

Gladys Varinia Salazar Cobeña ${ }^{1}$

RECIBIDO: 02/09/2021 ACEPTADO: 20/09/2021 PUBLICADO: 30/10/2021

1. Doctora en Ciencias Contables y Empresariales; Magister en Contabilidad y Auditoría; Economista; Docente de la Universidad Técnica de Manabí; Portoviejo; Manabí; Ecuador; varinia.salazar@utm.edu.ec; (D) https:/l orcid.org/0000-0002-7889-9111

CORRESPONDENCIA

Gladys Varinia Salazar Cobeña

varinia.salazar@utm.edu.ec

Manabí, Ecuador

() RECIMUNDO; Editorial Saberes del Conocimiento, 2021 


\section{RESUMEN}

Introducción: A partir de la declaratoria de emergencia sanitaria mundial por Covid-19 se adoptaron una serie de restricciones para intentar disminuir la propagación de este virus, lo cual no fue del todo efectivo, terminando en una verdadera pandemia con efectos hasta el momento devastadores en los distintos sectores de la sociedad, especialmente en el mercado laboral local e internacional. Objetivo: Elaborar un documento actualizado que contribuya a la ampliación teórica y argumentativa sobre la Covid-19 y el mercado laboral ecuatoriano. Metodología: Se llevó a cabo una revisión narrativa partiendo del análisis y recolección de información de 42 artículos científicos provenientes de bases de datos de acceso libre como Scielo, Dialnet, Latindex, utilizando el buscador google académico verificando las fuentes consultadas en una matriz bibliográfica con criterios de inclusión y exclusión. Conclusión: El aislamiento social obligatorio y el posterior distanciamiento social ha contribuido a disminuir la propagación de la covid-19, pero ha causado repercusión en el mercado laboral debido a la suspensión de actividades educativas, laborales y recreativas, que a nivel global siempre han sido las fuentes de ingresos de recursos que dinamizan la economía regional.

Palabras clave: Covid-19, Pandemia, Movilidad Laboral, Productividad, Impacto.

\section{ABSTRACT}

Introduction:Since the declaration of a global health emergency by Covid-19, a series of restrictions were adopted to try to reduce the spread of this virus, which was not entirely effective, ending in a true pandemic with devastating effects so far in the different sectors of society, especially in the local and international labor market. Objective: Prepare an updated document that contributes to the theoretical and argumentative expansion on Covid-19 and the Ecuadorian labor market. Method: A narrative review was carried out based on the analysis and collection of information from 42 scientific articles from open access databases such as Scielo, Dialnet, Latindex, using the academic google search engine, verifying the sources consulted in a bibliographic matrix with inclusion and exclusion criteria. Conclusions: Compulsory social isolation and subsequent social distancing has contributed to reducing the spread of covid-19, but has caused an impact on the labor market due to the suspension of educational, labor and recreational activities, which globally have always been the sources of income from resources that boost the regional economy.

Keywords: Covid-19, Pandemic, Labor Mobility, Productivity, Impact.

\section{RESUMO}

Introduction:Since the declaration of a global health emergency by Covid-19, a series of restrictions were adopted to try to reduce the spread of this virus, which was not entirely effective, ending in a true pandemic with devastating effects so far in the different sectors of society, especially in the local and international labor market. Objective: Prepare an updated document that contributes to the theoretical and argumentative expansion on Covid-19 and the Ecuadorian labor market. Method: A narrative review was carried out based on the analysis and collection of information from 42 scientific articles from open access databases such as Scielo, Dialnet, Latindex, using the academic google search engine, verifying the sources consulted in a bibliographic matrix with inclusion and exclusion criteria. Conclusions: Compulsory social isolation and subsequent social distancing has contributed to reducing the spread of covid-19, but has caused an impact on the labor market due to the suspension of educational, labor and recreational activities, which globally have always been the sources of income from resources that boost the regional economy.

Keywords: Covid-19, Pandemia, Mobilidade laboral, Produtividade, Impacto. 


\section{Introducción}

A nivel mundial se atraviesa una gran crisis sanitaria con colosales repercusiones en la salud y en la economía, a partir de la alerta emitida por la presencia de casos atípicos de patologías respiratorias graves desde diciembre del 2019 en la ciudad de Wuhan (China), extendiéndose a nivel mundial dando paso a una pandemia que hasta el momento tiene colapsado al mundo (Gorbalenya et al., 2020).

Esta pandemia ha golpeado en tiempos donde ha sido hegemónico un modelo de desarrollo con serios problemas estructurales: desigualdad creciente, alta informalidad en el mercado de trabajo, debilidad y fragmentación de sus instituciones, especialmente las relacionadas a la protección social, y una estructura productiva y empresarial con reducidas capacidades tecnológicas y concentrada en sectores dependientes de ventajas comparativas estáticas, como recursos naturales y bajos salarios. (Bárcena, 2020)

Presentándose la crisis económica en un entorno desfavorable tanto para las condiciones de la oferta como las de la demanda, con impactos agregados y sectoriales, causando fricciones comerciales, bajo crecimiento y una deuda abultada en la mayoría de las economías de los países afectados (Rogoff, 2020).

Los mercados laborales latinoamericanos resultan espacios complejos, atravesados por las heterogeneidades que informan sobre la propia región dejando en evidencia la vulnerabilidad y el riesgo de las inversiones, sobre todo cuando se presentan situaciones adversas como las crisis mundiales (Schteingart, 2018). En este sentido se comprende que la rápida expansión del virus por Covid-19, obligó a los gobiernos a adoptar fuertes medidas de contención que afectaron las tendencias convencionales en los mercados laborales, generando cambios tecnológicos diferenciados por la digitalización.

En este contexto, la crisis sanitaria propició la destrucción de empleos a causa del cierre de empresas y posesionó el uso de plataformas digitales que ocasionaron desempleo de personas con menores niveles de educación y habilidades en el uso de herramientas digitales, incrementando así la brecha laboral, desigualdad económica, laboral y de género.

Haciendo referencia a esta situación con el nivel de desempleo en Ecuador, que para diciembre de 2019 se ubicó en 3,8\%, en diciembre de 2020 en 5\%, posesionándose en mayo de 2021 en el 6,3\% (INEC, 2021a).

De manera que, este país se enfrenta a ingentes desafíos laborales para reactivar el sector productivo en un contexto de vulnerabilidad ante las políticas implementadas para salvaguardar el empleo formal e informal, cautelando los ingresos y priorizando el sector productivo.

Sin dejar de mencionar que la digitalización ha incrementado la sobrecarga laboral en hombres y mujeres, resultando estas últimas más afectadas por la intensificación laboral del teletrabajo y el cuidado del hogar, incidiendo en su productividad, bienestar y salud mental (Bidegain Ponte et al., 2020).

Sin duda alguna la crisis de la COVID-19 afecta de forma desproporcionada a las mujeres trabajadoras de muchas maneras, existiendo el riesgo de que se produzca un retroceso con respecto a algunos avances logrados en los últimos decenios, y de que se exacerbe la desigualdad de género en el mercado laboral

El objetivo de esta revisión narrativa consiste en elaborar un documento actualizado que contribuya a la ampliación teórica y argumentativa sobre la Covid-19 y el mercado laboral ecuatoriano. 


\section{Metodología}

En el presente trabajo de tipo descriptivo se realizó una revisión narrativa partiendo del análisis y recolección de información de 42 artículos científicos provenientes de bases de datos de acceso libre como Scielo, Dialnet, Latindex, utilizando el buscador google académico, organizando la información con el gestor bibliográfico Zotero, analizando sistemáticamente los artículos consultados empleando una matriz de análisis en base a criterios como antigüedad no mayor a 10 años, tendencia temática de acuerdo a los términos de búsqueda Covid-19, pandemia, movilidad laboral, productividad e impacto. Seleccionándose 30 artículos científicos que dan la relevancia y la fundamentación teórica de la presente revisión (anexo 1).

\section{Resultados}

\section{Pandemia y sus encrucijadas económi- cas, sociales y de género}

A inicios de 2020 la Organización Mundial de la Salud alertó sobre la existencia de cuadros respiratorios inusuales que obedecían a un virus identificado como SARSCoV-2, el cual se lo asoció como el causante de la enfermedad denominada Covid-19. (Deltell \& Claes, 2021). Posteriormente se propagó de forma rápida y progresiva este virus confirmándose nuevos casos en todo el mundo, llevando a los gobiernos a instaurar de manera obligatoria el aislamiento social, preventivo, el confinamiento, estados de excepción, las cuarentenas indefinidas con la finalidad de frenar la expansión de lo que meses más tarde se convertiría en la nueva pandemia que desde marzo del mismo año hasta la actualidad ha causado una de las mayores crisis sanitaria, sociales y económicas.

El shock de oferta derivado de las restricciones de empleo y de la obtención de suministros para las empresas, y el otro shock de demanda resultante de que los compra- dores no salieron a consumir o viajar; desencadenaron en marzo de 2020 la recesión de la economía mundial más dramática desde el final de la segunda guerra mundial (Iranzo, 2021).

Paralelamente las economías avanzadas experimentaron caídas del Producto Interno Bruto (PIB), entre los que se destacan Estados Unidos (-3,6\%); la Zona Euro $(-7,4 \%) ; y$, Japón (-5,3\%). A diferencia de China (2\%) que pese a presentar una recesión de su PIB registró una cifra positiva en medio de la pandemia en comparación con la mayoría de los países del mundo (Menz, 2021).

James (2020) afirma después de seis años de crecimiento sostenido España fue el país más afectado ya que su PIB decreció un $11 \%$ en 2020; seguido de Italia $(-8,8 \%)$; Francia (-8,3\%); y, Alemania (-5\%). Una de las principales causas reside en que estos países dependen en gran medida de los ingresos generados por sectores turísticos, comerciales y de transporte, los más afectados por la pandemia en España, Italia y Francia.

De acuerdo a proyecciones realizadas por la CEPAL (2021a) en América Latina y el Caribe el PIB decreció en un $7.7 \%$ en 2020 , representando la mayor contracción reportada desde 1900. En términos de agregados América del Sur experimentó una contracción promedio de 7,3\%, seguido por Centroamérica y México (8,5\%), y el Caribe (7,9\% o del10,8\% si se excluye Guyana). Bajo esta coyuntura económica, América Latina es una de las regiones más afectada por la crisis sanitaria, después de India, ya que según información proporcionada en abril de 2021 por el Fondo Monetario Internacional, la pérdida del PIB en América Latina representó el 7\%, considerándose la mayor pérdida desde la independencia equivalente a 7 años de crecimiento económico (Blanco, 2021). Estas cifras son resultado de la contracción de la demanda externa e interna y de las restricciones

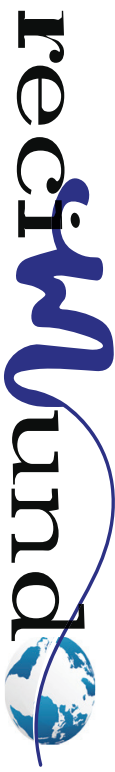


de la producción de bienes y servicios no esenciales como medida adoptada por estos países para hacer frente a la pandemia.

En 2020 la contracción promedio del PIB en América del Sur fue de un $7,7 \%$, con caídas económicas importantes como es el caso de Perú (-12,9\%), Argentina (-10,5\%), México $(-9 \%)$, Ecuador (-9\%), Bolivia (-8\%), CoIombia (-7\%), Chile (-6\%) y Brasil $(-5,3 \%)$, mientras que Venezuela decreció en un $30 \%$. A diferencia de economías de América Latina y el Caribe, Guyana experimentó un crecimiento de 30.9\% (CEPAL, 2021a).

Por otra parte, países de la región como Bolivia (-26\%), Perú (-22\%), Paraguay (-16\%), Ecuador (-10\%), Costa Rica (-10\%), Honduras $(-2 \%)$ y Colombia $(-1 \%)$, reportaron una evidente reducción de las remesas en los últimos años. Por el contario México hasta agosto de 2020 respecto al período anterior creció en un 9\% (CEPAL, 2021a).

El fuerte impacto de la pandemia en los niveles de pobreza por ingresos en el Ecuador ha privado a la población de satisfacer sus necesidades dignamente. En 2020 la línea de pobreza registrada en el país fue de 84,05 mensuales per-cápita, considerándose como pobres por ingresos a las personas con ingresos per cápita inferiores a esta línea de pobreza. El coeficiente Gini pasó de 0,473 a 0,500 del 2019 al 2020, evidenciando elevados niveles de desigualdad ante el incremento significativo de 0,027. Respecto de los niveles de pobreza se observó un incremento de 7,4 puntos porcentuales, pasando de 25,0\% en 2019 a 32,4\% en 2020 . Es decir, que en Ecuador 3 de cada 10 personas viven con menos de tres dólares diarios. (Ayala et al., 2021).

En efecto, los múltiples esfuerzos realizados en el último decenio para mitigar la pobreza y el hambre en la población ecuatoriana, fue desplomada en nueve meses por una crisis endémica sin precedentes derivada de casos importados de Covid-19, que activaron inmediatamente las alarmas de los países para combatir la propagación de la epidemia y ante la posibilidad de que se presenten nuevas variantes o mutaciones del virus con los elevados índices de letalidad para la humanidad.

Por otra parte, entre septiembre de 2019 y septiembre 2020 Ecuador experimentó una degradación de sus principales indicadores del mercado laboral, producto del desempleo, subempleo y de la informalidad con particularidades propias del empleo. Específicamente, en septiembre de 2020, 115.749 personas resultaron desempleadas (28\%) y 191.079 en condiciones de subempleo; existiendo así un incremento en las tasas de desempleo $(6,64 \%)$ y subempleo (23,4\%). Además, el $32,08 \%$ de la población económicamente activa (PEA) se encuentra en condición de pleno empleo lo que equivale a menos de un tercio de la PEA, provocando el 48,6\% de empleos informales en el país en comparación con el sector formal, y revelando un incremento interanual de dos puntos porcentuales (CEPAL, 2021a).

En consecuencia, muchas empresas ecuatorianas quebraron teniendo que suspender sus operaciones, dejando hogares sin empleos o con reducción en sus salarios. Además, de otras limitaciones del confinamiento que impidieron a hogares con mayores ingresos realizar viajes, participar en actividades de ocio o recreativas que hubieran contribuido a reactivar la economía. Consecuentemente, tal y como (Albuja, 2021) asevera la pandemia ha impactado en la disminución de los recursos de la población ecuatoriana como resultado de la paralización en las economías a nivel mundial, viéndose profundamente afectado el bienestar de las personas.

Para el 2021 se proyecta un leve crecimiento económico del país con una tasa del $1 \%$ del PIB. Esta lenta recuperación de la economía ecuatoriana deriva de las incertidumbres de 
las condiciones sanitarias por la pandemia, problemas de liquidez y de necesidad de financiamiento persistente para hacer frente a la crisis sanitaria (CEPAL, 2021a).

De acuerdo a las cifras de indicadores laborales publicadas por INEC (2021a) se reveló que en mayo 2021 la tasa de desempleo se ubicó en un $31,5 \%$, la tasa de subempleo en $23,1 \%$ y la tasa de desempleo en $6,3 \%$. Mientras que, la tasa de participación bruta a nivel nacional representó un 47,6\% (46,2\% en el área urbana y 50,6\% en el área rural). Por otra parte, la tasa de participación global fue de 66,9\% (63,6\% urbana $74,7 \%$ rural), de manera que ambas tasas resultaron superiores en el área rural, tanto a nivel nacional como urbano.

El desempleo a nivel nacional fue del 6,3\% (8,4\% urbana y 2,2\% rural). De esta tasa en la población económicamente activa el $7,2 \%$ de las mujeres se encontraron en condición de desempleo, en comparación al 5,6\% de los hombres, existiendo así una diferencia significativa de 1,5 puntos porcentuales en ambos géneros. Diferencia similar se observa en la tasa del empleo bruto a nivel nacional para hombres de $74,1 \%$ en relación al 51,9\% en mujeres (INEC, 2021a).

Durante el trimestre de enero a marzo de 2021 a nivel nacional, se reveló que el $45,9 \%$ de la totalidad de personas con empleo se encontraban en el sector formal, el $46,4 \%$ en el sector informal, de esta diferencia un $2 \%$ contaba con empleo doméstico y el $5,7 \%$ en la categoría de no clasificados por sector. Adicionalmente, se destaca que el $91,8 \%$ de la población son empleados privados y el $8,2 \%$ está compuesto por empleados públicos.

En lo respecta al subempleo nacional, se evidenció que el $61,5 \%$ del total de personas fueron hombres y el $38,5 \%$ restante mujeres, de los cuales el 0,4\% pertenece a empleados públicos y el 99,6\% a empleados privados. Además, de esta población en situación de subempleo el 24,2\% corresponde al sector formal, el $64 \%$ al sector informal, el 2,7\% a empleo doméstico y el 9,01\% no clasificado (INEC, 2021b).

A efectos de análisis se debe considerar las directrices internacionales que determinan que el sector informal está compuesto por personas que laboran en unidades productivas de menos de 100 trabajadores que no tienen Registro Único de Contribuyentes (RUC). Por el contrario, el mercado formal lo integran personas que laboran en establecimientos que poseen RUC. En lo que respecta a la categoría no clasificados, esta se compone por aquella población que no registra información en la pregunta de RUC respecto de la empresa en la que labora (INEC, 2015).

Santos et al. (2020) asegura que en el sector rural del mercado laboral ecuatoriano predomina la informalidad, existiendo una mayor propensión a que una persona que vive en el área rural trabaje en la agricultura, con educación primaria concluida, ingresos inferiores al salario formal y de sexo femenino.

Frecuentemente la pobreza afecta a mujeres y hombres, niñas y niños de diversas maneras, en función de su parentesco, edad, ciclo de vida, etnia, y género. Estas realidades de las mujeres, asociadas con su biología, sus roles de género y su subordinación culturalmente construida, las convierte en personas vulnerables que enfrentan condiciones desventajosas que se acumulan con otros efectos derivados de la misma pobreza (Pinela-Cruz et al., 2021)

En América Latina, la desigualdad de género en el hogar en tiempo de pandemia ha agigantado las brechas laborales de género que vulneran en mayor medida a las mujeres en relación a los hombres ante la pérdida del empleo y el incremento de la carga de trabajo no remunerado. Además, del trabajo no remunerado que les tocó asumir

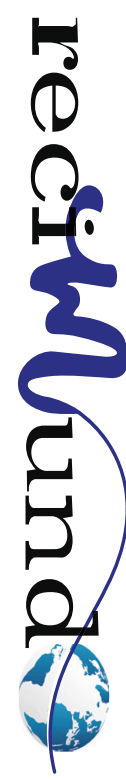


a las mujeres por el cierre generalizado de escuelas y guarderías. Las mujeres también se enfrentan a mayores riesgos de inseguridad económica en el mercado laboral en comparación con los hombres. Otro riesgo que enfrenta este género es la violencia doméstica durante la pandemia, a causa del encierro y confinamiento obligatorio (OECD, 2020).

Fajardo-Ronquillo (2020) expresa que en el Ecuador persisten brechas de género por cuanto la flexibilidad, existiendo discriminación por razones de sexo, en lugar que este grupo vulnerable sea valorado por su productividad y capacidades, y no por su condición de género como resultado de construcciones socioculturales que generan diversas inequidades para este grupo de personas.

En relación con este tema, la pandemia ha generado efectos sociales y de género a nivel mundial. En América Latina y el Caribe, la violencia de género contra las niñas y mujeres, se vieron afectadas y agravadas por las medidas de aislamiento, distanciamiento físico y restricciones de la movilidad que incrementaron las barreras de acceso a servicios esenciales (CEPAL, 2021b).

La dimensión del choque de la demanda agregada resultante de la abrupta reducción del consumo de bienes y servicios en sectores comerciales, de transporte, servicios empresariales, sociales, turísticos y de entretenimiento ante las medidas impuestas por los gobiernos e inclusive por el autoaislamiento y distanciamiento social adoptados por las personas, causaron fuertes problemas de liquidez. En este contexto, la virtualización de las relaciones económicas, laborales y sociales se potencializaron, predominando la digitalización a nivel mundial, existiendo una marcada brecha tecnológica e inteligencia artificial en empresas grandes, medianas y pequeñas (CEPAL, 2020b). Estos cambios en las relaciones laborales obligan a los gobernantes, directi- vos, empresarios, colaboradores del sector público, privado y social, a prepararse y anticiparse a las repercusiones de este nuevo escenario laboral y profesional (Vaquero, 2020).

Entre los efectos socioeconómicos de la Covid-19 se destaca la reducción del número de empleo, salarios, horas de trabajo y acceso a la seguridad social, llevando a muchos trabajadores y hogares a situaciones de pobreza principalmente a los grupos más vulnerables, entre los que se encuentra la población con problemas subyacentes, las personas mayores (antes denominados adultos mayores), jóvenes desempleados, personas desempleadas, mujeres, trabajadores informales, desprotegidos y migrantes, con los consiguientes aumentos en la pobreza y desigualdad entre regiones y grupos sociales (CEPAL, 2020b).

La pandemia ocasionada por COVID-19 mantiene en una situación difícil a los países de los distintos continentes, entre ellos al Ecuador, respecto de cómo adoptar medidas de afrontamiento a la crisis económica, social, política, cultural, laboral y digital. En que evidentemente, se ha expandido la vulnerabilidad de los derechos y oportunidades de las mujeres en el contexto patriarcal, recayendo las labores domésticas mayormente en este grupo de personas, sin olvidar el incremento de la violencia de género, empeorada por la situación de confinamiento y autoaislamiento social para no contraer la enfermedad.

Impacto en el mercado laboral latinoamericano por Covid-19

Las medidas adoptadas por los gobiernos de América Latina como respuesta a detener la expansión del virus impactaron en las tasas de empleo, desempleo y subempleo. En este sentido la reactivación del mercado laboral será un proceso lento y complejo, con alto predominio de la informalidad laboral que se contraponen al cumplimiento 
de los objetivos del desarrollo sostenible en el marco de garantizar la igualdad de oportunidades y una vida digna para todas las personas.

En términos globales la covid-19 ha impactado directamente en la oferta de trabajo, ya que en un primer momento para contener la expansión de la pandemia las personas contagiadas con el virus no podían ir a trabajar y el confinamiento obligatorio impidió a muchas empresas seguir operando, reduciéndose así los ingresos familiares y el consumo de los productos. Además de ello, la permanente incertidumbre provocó que las familias retraigan sus consumos como medida preventiva y que las empresas suspendan o retrasen sus planes de inversión por lo complejo de diversificar el consumo de productos no esenciales para la vida.

En un contexto de frágiles economías familiares, Sumba-Bustamante et al. (2020) sostiene que el desempleo implica una reducción de los ingresos de las familias, generando cambios radicales en su estilo de vida, y la incertidumbre de no saber cuánto tiempo persistirá esa situación ocasionó que las personas sean precavidas y reduzcan drásticamente los gastos. De esta problemática se deriva un efecto desproporcionado y perjudicial en los trabajadores empleados en sectores fuertemente golpeados como son la alimentación y hotelería, el minorista e inmobiliario.

Weller et al. (2020) explican que una de las ramas de la actividad laboral más afectada en tiempos de pandemia fue el trabajo doméstico. Además, los servicios que también sufrieron fuertes pérdidas económicas fueron los servicios de hospedaje, alimentos, construcción, entretenimiento, actividades comerciales, turísticas y artísticas. A diferencia de los servicios de salud, educación y administración pública que experimentaron menor contracción. Así mismo, se evidencia una tendencia hacia una mayor desigualdad en términos de pérdidas de empleo de trabajadores informales, con menor preparación académica y en grupos de ocupación de cualificación menor.

De acuerdo a lo expuesto por Chiodi (2021) el mercado laboral de América Latina ha experimentado una crisis sin precedentes a causa de la pandemia por COVID-19. Así lo demuestran los indicadores laborales que reportaron 34 millones de trabajadores en condición de desempleo. Las horas laboradas y los ingresos evidencian la drástica reducción del nivel de actividad económica en 2020 (-9,4\%), siendo esta situación alarmante por las brechas de desigualdad en niños, jóvenes, mujeres, trabajadores informales ( $80 \%$ de los trabajadores en el cuartil inferior) y autónomos.

Como se ha revelado en párrafos anteriores, la pandemia por COVID-19 ha representado pérdida de empleos y aumento generalizado de la desocupación en todo el mundo. En 2019 la desocupación ascendió a 33 millones de empleos, hasta alcanzar los 220 millones en 2020. Por su parte, la tasa de desocupación se incrementó en 1,1 puntos porcentuales, hasta llegar al 6,5\%. Mientras, la pérdida de horas de trabajo a escala mundial en el cuarto trimestre de 2020 fue de $8,6 \%$ equivalentes a 245 millones de empleos a tiempo completo. Consecuentemente en América Latina y el Caribe este indicador duplicó el promedio de horas de trabajo perdidas con 14,9\%. (Chiodi, 2021)

La Organización Internacional del Trabajo (OIT) a través de un estudio sobre la COVID-19 y el mundo del trabajo por sexo y edad reveló que a nivel de América Latina y el Caribe, en 2020 con respecto al 2019 existió una disminución de la ocupación (relación ocupación-población) del 6,1\% en mujeres; $6,6 \%$ en hombres; $6,2 \%$ en jóvenes; y; $6,4 \%$ en adultos. Así mismo, se evidenció una disminución en la fuerza laboral (tasa de actividad) de 5,5\% en mujeres; $5,3 \%$ en hombres; $6,1 \%$ en jóvenes y $5,3 \%$ en adultos. A diferencia de un aumento en

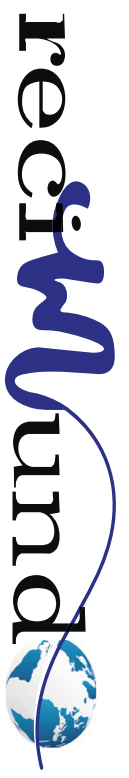


la tasa de desocupación del 2,4\% en mujeres; $2,3 \%$ en hombres; $2,7 \%$ en jóvenes; $y$, 2,3\% en adultos. (OIT, 2021)

Evidentemente la pandemia afectó en mayor proporción a las mujeres en comparación con los hombres en todas las regiones y con respecto a todos los grupos de ingresos. Así en 2020 respecto de 2019 la reducción del nivel ocupacional de la mujer en todo el mundo fue del 5\% (64 millones), de cara al 3,9\% en el caso de los hombres (80 millones), a causa de la disparidad de género demostradas desde hace tiempo por las tasas de participación en la fuerza laboral. (OIT, 2021)

Además la OIT (2021) destaca que para todas las regiones y para todos los grupos de ingresos por país los jóvenes trabajadores resultaron especialmente afectados por esta crisis en 2020, ante una caída de la ocupación del 8,7\%, en comparación del $3,7 \%$ de los adultos. No obstante, exceptuando los países de altos ingresos, los jóvenes sin empleo, o con posibilidad de acceder al mercado de trabajo a corto plazo, generalmente no pasaron a estar desocupados, sino que salieron de la no participación laboral, o retardaron su incorporación a la misma. Ello evidencia los motivos por los que la cantidad mundial de jóvenes desempleados no aumentó. No obstante, esta crisis ha agravado las dificultades de los jóvenes para ingresar al mercado de trabajo y demostrando el riesgo real que daría lugar a una generación perdida.

Tal y como Malpartida et al. (2021) aseguran a nivel latinoamericano Ecuador, fue uno de los países más afectado durante las primeras semanas en que se propagó la pandemia, de ahí que organismos internacionales manifiestan que el país enfrentará duras repercusiones económicas. Sin olvidar, que desde hace varias décadas el mercado laboral del Ecuador presenta serios problemas estructurales demostrados en el alto deterioro de los indicadores de empleo e ingresos, que vulneran la calidad de vida de los ecuatorianos. (Meneses et al., 2021).

Dentro de este marco según información estadística proporcionada por el Banco Central del Ecuador, la fuerte recesión económica ha impactado negativamente en los sectores estratégicos del país al existir un decrecimiento en sector agrícola (-2,9\%), industrial $(-6,1 \%)$, y financiero $(-0,9 \%)$. Ante ello, en junio de 2020 la Asamblea Nacional del Ecuador aprobó la Ley Orgánica de Apoyo Humanitario para combatir la crisis sanitaria derivada del Covid-19; pronosticando que para 2021 el sector agrícola crecerá en un 2,7\%, el industrial en $2,7 \%$ y el financiero en 0,7\%. (Huilca \& Baño, 2021)

En relación a la problemática expuesta, "la incorporación de nuevas tecnologías en el campo laboral ha permitido sustituir diversas prácticas y actividades destinadas a resolver toda clase de problemas relativos a la producción de bienes o la prestación de servicios" (Barrionuevo, 2021, p. 225). Es así como el teletrabajo forma parte del nuevo modelo familiar generando múltiples y severas consecuencias para las mujeres, ocasionando disyuntivas en el intento de hacer compatible el mundo laboral y el de índole familiar.(Pérez \& Gálvez, 2009)

Las epidemias y las crisis económicas impactan desproporcionadamente en los segmentos más vulnerables de una región, acrecentándose las debilidades existentes en término de pobreza, inequidad, exclusión laboral, social y educativa desde los hogares a través de la tecnología y modalidad virtual o remota, debido a que los trabajadores principalmente los autónomos no generan suficientes ingresos para satisfacer las necesidades fundamentales de alimentación, salud, educación, vestimenta y vivienda. (Avendaño-Castro et al., 2020)

En función de lo planteado en el contexto de la crisis sanitaria por COVID-19, América Latina y de manera particular Ecuador 
se enfrentan a ingentes desafíos en los sectores estratégicos con miras a alcanzar el desarrollo sostenible en términos de generación de empleo, equidad, crecimiento y desarrollo sustentable de las economías. Por consiguiente, estos retos deben orientarse a la reconstrucción de los mercados laborales que amparen los derechos de los trabajadores y garanticen remuneraciones justas que mejoren la productividad, competitividad y por ende la calidad de vida de sus habitantes.

Transformación y tendencias futuras del mercado laboral ecuatoriano como oportunidades frente a la crisis sanitaria

La crisis sanitaria a nivel mundial ha generado consecuencias negativas, dolorosas y desesperanzadoras en la población. Sin embargo, lo paradójico es que ha ocasionado oportunidades de emprendimiento, innovación, desarrollo y transformación tecnológica caracterizada por la digitalización en el corto y largo plazo.

Al respecto, (Soledispa et al., 2020) coincide al afirmar que a pesar de los vertiginosos avances de la tecnología continúan persistiendo las desigualdades de acceso a la educación entre países. Mientras que (Almeda \& Batthyány, 2021) explica que si bien las tecnologías de la información y comunicación son herramientas que brindan extraordinarios beneficios para la sociedad, la desproporción digital en el acceso, uso y apropiación social de estas tecnologías generan la exclusión de determinados grupos de personas en la sociedad de la información del conocimiento.

En relación a la problemática expuesta, los cambios tecnológicos han profundizado las brechas de desigualdad principalmente en aquellas personas con menores niveles de educación, menores ingresos, minorías de grupos étnicos y con diferentes habilidades digitales. (Weller, 2020)
En este marco por la pandemia también se profundizaron asimetrías de género y la vulnerabilidad de las mujeres en los hogares, empresas y en la sociedad, precisándose políticas y programas de cuidado que permitan atenuar esta realidad y que se fomente la corresponsabilidad entre mujeres y hombres en el entorno familiar, laboral y social de manera inmediata, ya que se trata de que las mujeres se incorporen al mercado laboral, académico, político y que pueda disfrutar completamente su autonomía. (Almeda \& Batthyány, 2021)

Además, las repercusiones generadas por la situación pandémica y las medidas para la recuperación que adopten las economías regionales para realizar modificaciones estructurales deben permitir transitar hacia un modelo inclusivo, sostenible y libre de racismo orientado a la igualdad de los derechos y oportunidades. (CEPAL \& UNFPA, 2021)

Desde esta perspectiva y en contraposición a las consecuencias sociales fatales ocasionadas por la pandemia, Latinoamérica y en especial para Ecuador, las oportunidades de aprendizaje son invaluables, puesto que ha propiciado oportunidades para incursionar en emprendimientos y dar paso a una avalancha de diversificación tecnológica fundamental para contrarrestar el aislamiento social y facilitar el funcionamiento de los sistemas económicos. (Useche et al., 2021)

En este contexto, a raíz de la crisis sanitaria ha sido más evidente la desigualdad económica derivada de la problemática estructural y multidimensional en la región, incrementándose sustancialmente las brechas en los ingresos de las familias y calidad de vida de la sociedad. Sin embargo, la transformación de la fuerza laboral de sectores con menores niveles de productividad como el agrícola hacia sectores mayormente productivos como el industrial, derivarían una contracción de las brechas de desigualdad. (Villamar, 2021)

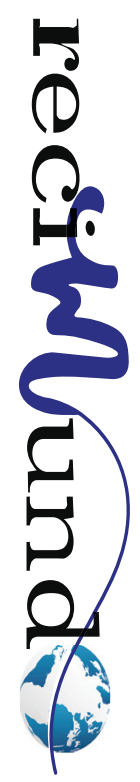


Por otra parte, ante la necesidad imperiosa de cambiar la modalidad de las actividades laborales presenciales a actividades virtuales, las empresas apresuraron el uso de soluciones y tecnologías digitales. Esto evidenció el incremento de las empresas con presencia en línea y en el cambio del tipo de presencia, puesto que se convirtieron en empresas con presencia pasiva (páginas web informativas) a presencias activas (sitios web transaccionales), lo que a su vez genera mayor segmentación productiva entre empresas con distintas capacidades. (CEPAL, 2021b)

La pandemia por la Covid-19 ha producido múltiples cambios en el mundo laboral que son claves para hacer compatibles una normalidad mejor. En este sentido, "las políticas para la recuperación deben apuntar no solo a una 'nueva normalidad' similar a la anterior, sino a una 'normalidad mejor' con mayor formalidad, equidad y diálogo social". (CEPAL, 2020a). En cualquier escenario, la nueva normalidad debe estar relacionada con mejores políticas laborales que no deterioren las condiciones de trabajo, basadas en la negociación colectiva y en la participación ciudadana responsable, dentro de un marco de beneficio común que mejoren las realidades de trabajo futuro.

García (2020) sostiene que la inteligencia artificial, la digitalización y la robótica, son unas de las cuestiones analizadas en torno al futuro del trabajo que generan una alta dosis de expectativa y especulación respecto de que puedan reducir drásticamente las oportunidades laborales. Al respecto, la (OTI, 2020) explica que sin lugar a duda los cambios tecnológicos han alterado la composición de los empleos y las habilidades necesarias para ejecutarlo. De las cuales, las habilidades socioemocionales, cognitivas no rutinarias y las digitales serán esenciales para alcanzar una inserción laboral exitosa en los empleos del futuro.
En resumen, los países implementaron estrategias para detener la propagación del virus como la adopción del teletrabajo repentino, inesperado y a gran escala, labor que resultaría simple ya que implicaba simplemente trasladar las tareas o actividades de los trabajadores desde sus oficinas a sus domicilios. No obstante, este cambio no resulta tan sencillo como comúnmente se piensa, ya que las personas confinadas en sus casas, realizaron sus labores sin recursos ni preparación y haciéndose cargo de sus hijos en ausencia de las instituciones educativas. Aunque se destaca que esta urgencia permitió salvar a empresas y puestos laborales, el costo ha sido alto ante una realidad que difiere de lo esperado. (Valenzuela-García, 2020)

De lo anterior, se puede deducir que la pandemia por covid-19 incrementó la necesidad de que las personas posean habilidades digitales como requisito clave para incorporarse o mantenerse funcionales en los mercados laborales. Más aún cuando las perspectivas futuras demandan empresas que se encuentran innovando tecnologías avanzadas y amigables con el ambiente en sus procesos productivos con miras al desarrollo sostenible.

En el mismo orden de ideas, Giuzio \& Cancela (2021) recalcan que ante las desventajas significativas que experimentan las mujeres en el mercado de trabajo en términos de equidad de género, se hace ineludible la incorporación de la perspectiva de género en las regulaciones del teletrabajo, para dejar atrás estereotipos de género atribuidos exclusivamente a las mujeres, incrementando así las desigualdades en el mercado laboral.

Indiscutiblemente en el contexto de la crisis sanitaria América Latina y de manera particular el Ecuador tienen como desafío replantear políticas laborales basadas en un enfoque de género que ampare los derechos de las personas y garanticen ingresos 
suficientes para mejorar la productividad, la competitividad local y por ende la calidad de vida de la población, bajo un contexto dolarizado, con elevado predominio de la informalidad y con dramáticos efectos causados por una pandemia que persiste a nivel mundial.

\section{Discusión}

De acuerdo a la metodología empleada para la presente revisión de los artículos consultados que fueron un total de 37 , se logró determinar la tendencia que estos presentan según los referentes teóricos desarrollados. Siendo así que, en el referente Pandemia y sus encrucijadas económicas, sociales y de género, se revelaron los principales problemas económicos, laborales y sociales a nivel macro, meso y micro derivados de la pandemia por Covid-19. De manera que la situación producida por esta enfermedad más allá de generar riesgos ha afectado de forma dramática y devastadora a la mayor parte de los sectores de las economías, cambiando la perspectiva del sistema de empleo e incrementándose las situaciones de vulnerabilidad física, social y psicológica.

Respecto del mercado laboral latinoamericano por Covid-19, se reveló el alto impacto directo y negativo que tuvieron las fuertes medidas adoptadas por los gobiernos en su intento para contener la expansión de esta enfermedad, derivando altas tasas de pérdida de empleos y aumento generalizado de la desocupación a nivel mundial, con un alto predominio en la informalidad de la oferta laboral. Además, se describió cómo esta problemática provocó una profunda contracción en los ingresos y por ende en el consumo, ahorro, inversión y en calidad de vida de las personas.

Finalmente, la transformación y tendencias futuras del mercado laboral ecuatoriano como oportunidades frente a la crisis sanitaria, revelaron que las tecnologías de la información y comunicación son herramientas claves para el crecimiento y desarrollo económico de una región en el corto y largo plazo. Sin embargo, el acceso, uso y apropiación de las tecnologías han profundizado las inequidades sociales principalmente en personas con menores ingresos, niveles académicos y competencias digitales diferentes.

\section{Conclusiones}

Las inequidades de género se acentúan en los hogares con menores ingresos haciendo evidente la asimetría del poder ejercido desde los micromachismos hasta su máxima expresión como lo es la cultura patriarcal; que a pesar de la ya difícil situación generada por la pandemia ha llegado a índices que han obligado a la mujer a extender sus jornadas de trabajo hacia labores domésticas, retrocediendo espacios ganados en materia de derechos y oportunidades, anclándola a un moderno sistema de esclavitud derivado de un fenómeno de exclusión social, económico y cultural a propósito de la pandemia actual.

El Ecuador desde hace varias décadas experimenta serios problemas estructurales demostrados a través de indicadores laborales, de ahí que la economía ecuatoriana a nivel latinoamericano ha sido una de la más afectadas a consecuencia de la pandemia por Covid-19. En efecto, el impacto de esta enfermedad en los mercados de trabajo incrementa la necesidad de intercambiar ideas sobre las posibles soluciones relacionadas con la regulación laboral de universalización de la protección social y de formalización de empleo que mejor se adapten a las aceleradas transformaciones del mercado laboral en que el Estado juega un rol elemental en tiempos de pandemia, ya que se debe dejar de responsabilizar únicamente a las personas de su autocuidado y condición de desempleo. 
Las tecnologías de la información y comunicación en tiempo de pandemia se han convertido en herramientas idóneas e imprescindibles en las actividades domésticas, educativas y laborales en todos los sectores de la sociedad. En prospectiva la transformación tecnológica caracterizada por la digitalización representa una ventaja competitiva que permitirá transformaciones empresariales y sociales en época pandémica y post pandemia. De ahí, la necesidad de que el Estado asegure mediante regulaciones condiciones de trabajo dignas para todas las personas que presten sus servicios bajo cualquier modalidad (presencial, semipresencial y a distancia) y programas para que permitan potenciar el mercado laboral.

\section{Bibliografía}

Albuja, W. (2021). Evaluación ex ante de la renta básica en Ecuador: Efectos en pobreza y desigualdad. El Trimestre Económico, 88(351), 807-830. https://doi.org/10.20430/ete.v88i351.1142

Almeda, E., \& Batthyány, K. (2021). Género, desigualdades sociales y pandemia por Sars-Cov-2. RES. Revista Española de Sociología, 30(3), 12. https://dialnet.unirioja.es/servlet/articulo?codigo $=7988216$

Avendaño-Castro, W., Hernandez-Suarez, C., \& Prada-Nuñez, R. (2020). Impacto social del Covid-19 en un contexto de informalidad. Revista ESPACIOS, 41(42), 39-51. https://doi.org/10.48082/espacios-a20v41n42p04

Ayala, J., Correa, L., \& John, C. (2021). Indicador de pobreza por ingreso en Ecuador y el efecto Covid-19, del 2010 al 2020. Sociedad \& Tecnología, 4(2), 248-264. https://doi.org/10.51247/st.v4i2.108

Bárcena, A. (2020). ALC ante la crisis del COVID-19: Cómo debe ser la reactivación. Pensamiento iberoamericano, 3(9), 12-23. https://dialnet.unirioja. es/servlet/articulo?codigo $=7596932$

Barrionuevo, J. (2021). El efecto del teletrabajo en el empleo en Ecuador durante la crisis sanitaria 2019-2020. Sociedad \& Tecnología, 4(2), 223-234. https://doi.org/10.51247/st.v4i2.106

Bidegain Ponte, N., Scuro Somma, L., \& Vaca-Trigo, I. (2020). La autonomía económica de las mujeres en tiempos de COVID-19. Revista CEPAL, 132, 225-238. https://repositorio.cepal.org/hand- le/11362/46833

Blanco, A. (2021). América Latina post COVID-19: Riesgos y oportunidades del nuevo ciclo económico-Elcano [Estudios internacionales y estratégicos]. Real Instituto el Cano. http://www. realinstitutoelcano.org/wps/portal/rielcano_es/ contenido?WCM_GLOBAL_CONTEXT=/elcano/elcano_es/zonas_es/ari65-2021-blanco-america-latina-post-covid-19-riesgos-y-oportunidades-nuevo-ciclo-economico

CEPAL. (2020a). Para que la reactivación productiva y del empleo post COVID-19 sea segura y saludable, se requiere priorizar las políticas de seguridad y salud en el trabajo. CEPAL. https://www.cepal. org/es/comunicados/que-la-reactivacion-productiva-empleo-post-covid-19-sea-segura-saludable-se-requiere

CEPAL. (2020b). América Latina y el Caribe ante la pandemia del COVID-19: Efectos económicos y sociales (Informe Especial COVID-19 N.o 1; p. 15). Comisión Económica para América Latina y el Caribe (CEPAL). https://repositorio.cepal.org/ handle/11362/45337

CEPAL. (2021a). Balance Preliminar de las Economías de América Latina y el Caribe 2020 (Informe anual Anual; p. 163). Comisión Económica para América Latina y el Caribe (. https://www.cepal. org/es/publicaciones/46501-balance-preliminar-economias-america-latina-caribe-2020

CEPAL. (2021b). La paradoja de la recuperación en América Latina y el Caribe. Crecimiento con persistentes problemas estructurales: Desigualdad, pobreza, poca inversión y baja productividad (Informe especial Covid-19 N.o 11; p. 42). Comisión Económica para América Latina y el Caribe (CEPAL). https://www.cepal.org/es/publicaciones/47043-la-paradoja-la-recuperacion-america-latina-caribe-crecimiento-persistentes

CEPAL, N., \& UNFPA. (2021). Afrodescendientes y la matriz de la desigualdad social en América Latina: Retos para la inclusión. Síntesis. CEPAL. https:// repositorio.cepal.org/handle/11362/46870

Chiodi, V. (2021, mayo). COVID-19 y desigualdades en América Latina: ¿revés de fortuna? 8(1), 2329. http://repositorio.flacsoandes.edu.ec/handle/10469/17160

Deltell, L., \& Claes, F. (2021). Conocimiento libre en tiempos de pandemia. Estudio de los artículos "Covid-19" y "Pandemia por Covid-19" en Wikipedia*. Interface - Comunicação, Saúde, Educação, 25(1), e200329. https://doi.org/10.1590/interface.200329 
Fajardo-Ronquillo, V. P. (2020). Condiciones del empleo formal e informal en Ecuador. Dominio de las Ciencias, 6(2), 279-294. https://doi.org/10.23857/ pocaip

García, C. (2020). Futuro y perspectivas del trabajo en el marco del Covid-19. Revista Jurídica Mario Alario D'Filippo, 12(24), 399-409. https://dialnet. unirioja.es/servlet/articulo?codigo $=7630971$

Giuzio, G., \& Cancela, M. (2021). Teletrabajo e inequidades de género. Relaciones Laborales y Derecho del Empleo, 9(1), 410-426. http://ejcls. adapt.it/index.php/rlde_adapt/article/view/958

Gorbalenya, A. E., Baker, S. C., Baric, R. S., Groot, R. J. de, Drosten, C., Gulyaeva, A. A., Haagmans, B. L., Lauber, C., Leontovich, A. M., Neuman, B. W., Penzar, D., Perlman, S., Poon, L. L. M., Samborskiy, D., Sidorov, I. A., Sola, I., \& Ziebuhr, J. (2020). Severe acute respiratory syndrome-related coronavirus: The species and its viruses - a statement of the Coronavirus Study Group. BioRxiv, 2020.02.07.937862. https://doi. org/10.1101/2020.02.07.937862

Huilca, D., \& Baño, Á. (2021). La Reactivación de la Economía Ecuatoriana durante la Pandemia por COVID - 19. Revista Jurídica Crítica y Derecho, 2(3), 79-89. https://doi.org/10.29166/cyd. v2i3.3191

INEC. (2015). Revista de Estadística y Metodologías [Ecuador en cifras]. Instituto Nacional de Estadística y Censos. https://www.ecuadorencifras.gob.ec/ revista-de-estadistica-y-metodologias/

INEC. (2021a). Empleo - Mayo 2021 [Gubernamental]. Instituto Nacional de Estadística y Censos. https://www.ecuadorencifras.gob.ec/empleo-mayo-2021/

INEC. (2021b). ENEMDU - Trimestral enero-marzo 2021: Mercado Laboral Trimestre enero-marzo 2021 (Boletín técnico № 05-2021-ENEMDU; p. 13). Instituto Nacional de Estadísticas y Censos. https://www.ecuadorencifras.gob.ec/enemdu-trimestral-enero-marzo-2021/

Iranzo, S. (2021). Revista Economistas del Colegio de Economistas de Madrid. CEMAD, 172/173, 338. https://dialnet.unirioja.es/servlet/articulo?codigo $=7889306$

James, J. (2020). Informe sobre la Evolución de la Economía Mundial (Informe sobre la Evolución de la Economía Mundial N.o 3; pp. 18-23). http:// www.ciem.cu/Informe\%20Sobre\%20la\%20Economia\%20Mundial.html

Malpartida, J., Mato, R., Satalaya, K., Huaripata, Y., Ramos, L., \& Díaz, J. (2021). Crisis Laboral en tiempos de COVID-19. Llamkasun, 2(3), 45-63. https://doi.org/10.47797/llamkasun.v2i3.54

Menz, E. (2021). Impactos Económicos y Sociales a un año de la pandemia por COVID-19 en América Latina y el Caribe. FLACSO. https://flacsochile. org/publicaciones/documento-de-trabajo/impactos-economicos-y-sociales-a-un-ano-de-la-pandemia-por-covid-19-en-america-latina-y-el-caribe/

OECD. (2020). OECD Employment Outlook 2020: Worker Security and the COVID-19 Crisis | OECD iLibrary. OECD. https://www.oecd-ilibrary.org//site s/1686c758-en/1/3/1/../../../../els-2020-379-en/index.html

OIT. (2021). La COVID-19 y el mundo del trabajo. Estimaciones actualizadas y análisis [Nota informativa]. http://www.ilo.org/global/topics/coronavirus/ impacts-and-responses/WCMS_767045/lang--es/ index.htm

OTI. (2020). Panorama Laboral 2019. América Latina y el Caribe (p. 152) [Informe]. http://www.ilo.org/ americas/publicaciones/WCMS_732198/lang--es/ index.htm

Pérez, C., \& Gálvez, A. (2009). Teletrabajo y vida cotidiana: Ventajas y dificultades para la conciliación de la vida laboral, personal y familiar. Athenea Digital. Revista de pensamiento e investigación social, 15, 57-79. https://atheneadigital.net/article/ view/n15-perez-galvez

Pinela-Cruz, C., Pacheco-Castro, L., \& Soledispa-Cañarte, B. (2021). Clases sociales, pobreza y desigualdad en la sociedad ecuatoriana postcovid-19. Polo del Conocimiento, 6(3), 1116. http:// dx.doi.org/10.23857/pc.v6i3.2424

Rogoff, K. (2020). Recuerdos de los setenta | by Kenneth Rogoff. Project Syndicate. https://www. project-syndicate.org/commentary/next-global-recession-hits-the-supply-side-by-kenneth-rogoff-2020-03/spanish

Santos, R., Perez, L., \& Delgado, J. (2020). Sector Informal en Ecuador: Perspectiva desde el Escenario Econométrico. Revista ESPACIOS, 41(14), $17 . \quad \mathrm{http} / / / \mathrm{www}$. revistaespacios.com/ a20v41n14/20411417.html

Schteingart, D. (2018). El rompecabezas del mercado laboral latinoamericano. Revista Nueva Sociedad. https://www.relatsargentina.com/documentos/RA.1-PES/RELATS.A.PES.Scheingart1.pdf

Soledispa, B., Avilés, P., \& Rivera, G. (2020). Desafíos que afrontar para el mundo post pandemia. E-IDEA Journal of Business Sciences, 2(6), 12-21. https://revista.estudioidea.org/ojs/index.php/eidea/article/view/36 
Sumba-Bustamante, R. Y., Saltos-Ruiz, G., Rodríguez-Suarez, C., \& Tumbaco-Santiana, Z. (2020). El desempleo en el ecuador: Causas y consecuencias. Polo del Conocimiento, 5(10), 774. http://dx. doi.org/10.23857/pc.v5i10.1851.

Useche, M., Vásquez, L., Salazar, F., \& Ordóñez, M. (2021). Fórmula Estratégica Empresarial para Pymes en Ecuador ante el Covid-19. Revista Universidad y Empresa, 23(40), 1-22. https://doi. org/10.12804/revistas. urosario.edu.co/empresa/a.9309

Valenzuela-García, H. (2020). Teletrabajo y amplificación de la desigualdad en la sociedad post-pandemia española. Revista Andaluza de Antropología, 19, 14-36. https://dx.doi.org/10.12795/ RAA.2020.19.02

Vaquero, A. (2020). Nuevos retos laborales ante la digitalización: Un análisis desde la perspectiva económica. Temas laborales: Revista andaluza de trabajo y bienestar social, 1(151), 311-326. https://dialnet.unirioja.es/servlet/articulo?codigo $=7464156$

Villamar, A. (2021). Desigualdad y crecimiento económico en Ecuador, ¿se cumple la hipótesis de Kuznets? Yachana Revista Científica, 10(2), 114128. http://revistas.ulvr.edu.ec/index.php/yachana/article/view/688

Weller, J., Gómez Contreras, M., Martín Caballero, A., \& Ravest Tropa, J. (2020). El impacto de la crisis sanitaria del COVID-19 en los mercados laborales latinoamericanos. https://repositorio.cepal.org/ handle/11362/45864

Weller, Jürgen. (2020). La pandemia del COVID-19 y su efecto en las tendencias de los mercados laborales (Documentos de Proyectos (LC/TS.2020/67; pp. 3-31). Revista CEPAL. https://repositorio.cepal.org//handle/11362/45759

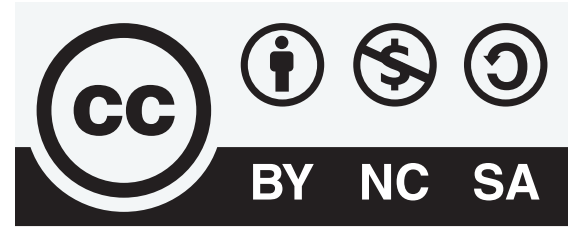

CREATIVE COMMONS RECONOCIMIENTO-NOCOMERCIAL-COMPARTIRIGUAL 4.0.

\section{CITAR ESTE ARTICULO:}

Salazar Cobeña, G. V. (2021). COVID-19 y mercado laboral ecuatoriano: Impacto, esperanzas y oportunidades. RECIMUNDO, 5(1 (Suple), 60-74. https://doi. org/10.26820/recimundo/5.(Suple1).oct.2021.60-74 